\title{
Market Integration and Strike Activity
}

A. Mauleon and V. Vannetelbosch

Discussion Paper 2005-25

Département des Sciences Économiques

de l'Université catholique de Louvain 


\title{
Market Integration and Strike Activity*
}

\author{
Ana Mauleon \\ FNRS and CEREC, \\ Vincent Vannetelbosch ${ }^{\dagger}$ \\ FNRS and CORE, \\ Facultés Universitaires Saint-Louis; Université catholique de Louvain. \\ and CORE.
}

April 2005

\begin{abstract}
We consider a two-country model of wage determination with private information in unionized imperfectly competitive industries. We investigate the effects of separated product markets opening up for competition as well as of further market integration on the negotiated wage and the maximum delay in reaching an agreement. From an initial situation of reciprocal intra-industry trade, an increase in product market integration will decrease the maximal delay in reaching an agreement. However, markets opening up for competition have an ambiguous effect on both the wage outcome and the maximum real delay time in reaching an agreement.

Keywords: economic integration, product market competition, wage bargaining, strike activity.
\end{abstract}

JEL Classification: C78, F15, J50, J52, L13.

\footnotetext{
*Ana Mauleon and Vincent Vannetelbosch are Research Associates of the National Fund for Scientific Research (FNRS), Belgium. Vincent Vannetelbosch is Associate Fellow of CEREC, Facultés Universitaires Saint-Louis.

${ }^{\dagger}$ Corresponding author address: CORE, Université catholique de Louvain, Voie du Roman Pays 34, B1348 Louvain-la-Neuve, Belgium. E-mail: vannetelbosch@core.ucl.ac.be, Tel: 0032-10-474142, Fax: 003210-474301.
} 


\section{Introduction}

The labour market implications of European integration are of considerable importance. Since labour is not very mobile in Europe, the effects of international integration on labour markets are mostly indirect via product market integration. More competitive product markets would reduce the power in national labour markets, making them more competitive. Andersen, Haldrup and Sørensen (2000) have found that integration gradually changes labour market structures and induces wage convergences as well as stronger wage interdependencies in wage formation among European countries. ${ }^{1}$

Empirical literature suggests that industry-specific factors are key determinants of strike activity. Key determinants are, among others, the type of industry, the industry or market size, the industry concentration, and the international competition. See e.g. Tracy (1986), Abowd and Tracy (1989), Cramton and Tracy (1994) who have studied the determinants of U.S. labor disputes. Despite this evidence, the theoretical literature on wage bargaining in industries with market power has neglected the analysis of the relationship between strike activity and market integration.

In the present paper we investigate the effects of separated product markets opening up for competition as well as of further market integration on wages and strikes. ${ }^{2}$ In order to do it, we consider a two-country model of wage determination with private information in unionized imperfectly competitive industries.

In the literature, product market integration has been interpreted as a reduction in costs associated with international trade: transport costs, tariffs, taxes, information costs about foreign markets, etc. These costs could be divided into fixed costs or start up costs associated with exporting, and variable costs proportional to the level of exports. Naylor (1998) has shown that a decrease in variable export costs may give rise to a higher wage since a monopoly union responds by increasing the wage rate to the increased employment's demand. However, Huizinga (1993) and Sørensen (1993) have shown that a decrease in fixed costs, that implies the move from autarchy to fully integrated markets, would increase the degree of competition in the product market and, as Dowrick (1989)

\footnotetext{
${ }^{1}$ Cutcher-Gershenfeld, Kochan and Calhoun-Wells (1998) have examined for the U.S. union and management perceptions of factors heavily influencing negotiations or the process in collective bargaining and its outcomes. The observations suggest that, beside other factors such as falling real wages, fear of job loss, and increased domestic competition, the increased international competition is a central feature motivating the parties to reach agreements.

${ }^{2}$ Mauleon and Vannetelbosch (2003) have analyzed in a closed oligopolistic industry how product differentiation and market competition affect the actual strike duration and the efficiency loss incurred during wage negotiations. If bargaining takes place at the firm-level, strike activity is increasing with the degree of product differentiation and is smaller under Bertrand than under Cournot competition.
} 
predicted, would reduce wages. More recently, Munch and Skaksen (2002) have shown that a reduction in fixed costs leads to an unambiguous decrease in wages, whereas a reduction in variable trade costs has an ambiguous effect on wages, due to the fact that the introduction of international competition for some goods neutralizes the effect on the employment's demand.

But, all these previous papers have used complete information models which predict efficient outcomes of the bargaining process. In particular agreement is always settled immediately, so that strikes cannot occur at equilibrium. ${ }^{3}$ This is not the case once we introduce private information into the wage bargaining, in which the first rounds of negotiation are used for information transmission between the two negotiators. The main feature of our model is that both the union and the firm have private information. Our model enables us to study the impact of product markets opening up for competition as well as of further market integration on wages and strikes. To describe the wage bargaining process, we adopt Rubinstein's (1982) alternating-offer bargaining model with two-sided incomplete information, which allows the occurrence of strikes at equilibrium.

From an initial situation of reciprocal intra-industry trade, we show that an increase in product market integration will have an ambiguous effect on wages even in case of bargaining with complete information. In this case, if markets are weakly integrated, an increase in product market integration will decrease wages. However, if markets are strongly integrated, an increase in product market integration will increase wages. This ambiguous relationship between wages and market integration is observed both when unions maximize the surplus as in Naylor (1998) or when unions simply maximize the wage. Naylor (1998) has shown that an increase in product market integration will unambiguously increase wages whenever only unions decide over wages. Thus, Naylor's results with a monopoly union are not robust to a right-to-manage model where the union and the firm negotiate over the wage. With respect to strike activity, we show that an increase in product market integration will decrease the maximal delay in reaching an agreement.

We also compare the situation where markets are separated to the one where markets are fully integrated. In case of bargaining with complete information, wages and prices will decrease while consumer surplus, profits and total quantities sold in each country will increase. But, once the union and the firm have private information, the wage outcome when markets are fully integrated is not necessarily smaller than the wage outcome when markets are separated. Moreover, markets opening up for competition have an ambiguous effect on the maximum real delay time in reaching an agreement. Indeed, each union-firm

\footnotetext{
${ }^{3}$ Strikes data seem to have a significant impact on the wage-employment relationship for collective negotiations. See Kennan and Wilson $(1989,1993)$ for surveys of bargaining models with private information and their relation to strike data. See Kennan (1986) for a survey of the empirical results on strike activity.
} 
pair expects to be able to alter its relative wage position in order to gain a larger share of the product market in each country. ${ }^{4}$ This incentive is stronger the more integrated the markets are since now a wage decrease makes the union-firm pair winning a more substantial market share of its rival. This explain why it is likely that more concessions and less conflicts in wage negotiations would occur once markets become integrated. However, markets opening up raise the potential payoffs for the union and the firm, and in expanding the payoff set (or range of possible payoffs), also increase the scope for delay (longer strikes and lockouts may be needed for screening the private information).

The paper is organized as follows. In Section 2, the model is presented. Section 3 describes the wage bargaining game and solves this game for the case of complete information. It also analyses the relationship between wages and market integration. Section 4 is devoted to the wage bargaining game with private information. Section 5 derives the maximal delay in reaching an agreement. Finally, Section 6 concludes.

\section{The model}

Following Naylor (1998), we assume that there are two identical countries ( $A$ and $B$ ) and that in each country there is one firm (firm 1 in country $A$ and firm 2 in country $B$ ) producing some homogeneous good. We assume that product demand is linear:

$$
\begin{aligned}
& P_{A}=a-b\left(X_{1 A}+X_{2 A}\right), \\
& P_{B}=a-b\left(X_{1 B}+X_{2 B}\right),
\end{aligned}
$$

where $P_{i}$ is the price of the homogeneous good in country $i, X_{1 A}$ is production by firm 1 for consumption in country $A, X_{2 A}$ is production by firm 2 for consumption in country $A$, $X_{1 B}$ is production by firm 1 for consumption in country $B, X_{2 B}$ is production by firm 2 for consumption in country $B$. There is a constant cost of $T$ per unit of the commodity exported. We interpret this cost as capturing all costs associated with international trade, such as transactions, transport and tariff costs. Let $\bar{T}$ be the upper limit on $T$ such that for $T \leq \bar{T}$ there is intra-industry trade in which both $X_{1 B}>0$ and $X_{2 A}>0$. We will mainly focus on three cases: markets are fully integrated $(T=0)$, markets are integrated $(T \in(0, \bar{T}])$, or markets are separated $(T=\infty)$. Each firm regards each country as a separate market and chooses the profit-maximizing quantity for each market separately, and on the Cournot assumption that the other firm's output in each market is given.

\footnotetext{
${ }^{4}$ Davidson (1988) and Horn and Wolinsky (1988) were first to study the impact of wage spillover effects on the interaction of union-firm bargaining and duopolistic quantity-setting. Dowrick (1989) has studied how product market power and profitability are related to wages.
} 
Production technology exhibits constant returns to scale with labour as the sole input and is normalized is such a way that $\left(X_{i A}+X_{i B}\right)=L_{i}$, where $L_{i}$ is labour input. The total labour cost to firm $i$ of producing quantity $\left(X_{i A}+X_{i B}\right)$ is $\left(X_{i A}+X_{i B}\right) \cdot W_{i}$, where $W_{i}$ is the wage in firm $i$. Thus, firm 1's profits and firm 2's profits can be, respectively, written as

$$
\begin{aligned}
& \Pi_{1}=\left(P_{A}-W_{1}\right) X_{1 A}+\left(P_{B}-W_{1}-T\right) X_{1 B}, \\
& \Pi_{2}=\left(P_{A}-W_{2}-T\right) X_{2 A}+\left(P_{B}-W_{2}\right) X_{2 B},
\end{aligned}
$$

where $T$ is the constant unit trade cost. Each firm is unionized and each union is assumed to maximize the wage rate. The reservation wage is set equal to zero in each country. ${ }^{5}$ Hence,

$$
U_{1}=W_{1} \text { and } U_{2}=W_{2} .
$$

This would imply that the union places no weight on employment. Although this may seem implausible, the notion that, in negotiating wages, unions do not take into account the employment consequences of higher wages has a long tradition including the influential work of Ross (1948), and is often stated by union leaders today (Pencavel, 1991). This assumption is made to obtain closed-form solutions in order to carry out the analysis under incomplete information. Cramton and Tracy (2003) have concluded that disputes largely are motivated from the presence of private information and the sharply conflicting interests of the union and the firm over the wage. In the appendix we show that our results under complete information are robust to an alternative specification where unions maximize the economic rent $L_{i} W_{i}$. Moreover, Mauleon and Vannetelbosch (2005) have shown that, if the union is not too strong (in fact, the range of union bargaining power we will consider), it is optimal for the union that maximizes the rents to send to the negotiation table delegates who maximize the wage. ${ }^{6}$

Interactions between market integration and wage bargaining are analyzed according to the following game structure. In stage one, wages are negotiated at the firm-level in both countries. Within each country the union and the firm negotiates a wage taking as given the wage set in the other country and taking into account the firm's labour

\footnotetext{
${ }^{5}$ It can be shown that all results are qualitatively robust to this assumption.

${ }^{6}$ Mauleon and Vannetelbosch (2005) have developed a model of wage determination with private information, in which the union has the option to delegate the wage bargaining to either surplus-maximizing delegates or to wage-maximizing delegates (such as senior union members). Mauleon and Vannetelbosch (2004) have considered a unionized duopoly model to analyze how unions affect the incentives for merger when surplus-maximizing unions have the option to delegate the wage bargaining to wage-maximizing delegates (such as senior union members). One of their results is that, in case of linear demands, the union in each firm will choose a wage-maximizing delegate if and only if the union bargaining power is not too strong, $\alpha \leq .81$.
} 
demand function. In stage two, each firm chooses its output (and hence employment) levels for the separate product markets, taking as given both (i) the output decisions of the other firm and (ii) the negotiated wages. The two-stage game makes the model an appropriate description of a situation in which wages are determined for a relatively long period while production decisions are made for a relatively shorter period. The model is solved backwards.

In the last stage of the game, the wage levels have already been determined. Both firms compete by choosing simultaneously their outputs (and hence, employment) to maximize profits with price adjusting to clear the market. In case markets are integrated, the unique Nash equilibrium of this stage game yields:

$$
\begin{aligned}
& X_{1 A}(T)=\max \left[\frac{a+T-2 W_{1}+W_{2}}{3 b}, 0\right], \\
& X_{2 A}(T)=\max \left[\frac{a-2 T-2 W_{2}+W_{1}}{3 b}, 0\right], \\
& X_{1 B}(T)=\max \left[\frac{a-2 T-2 W_{1}+W_{2}}{3 b}, 0\right], \\
& X_{2 B}(T)=\max \left[\frac{a+T-2 W_{2}+W_{1}}{3 b}, 0\right] .
\end{aligned}
$$

The Nash equilibrium outputs of a firm (and hence, equilibrium level of employment) are decreasing with its own wage, but are increasing with the other firm's wage and total industry demand.

In case markets are fully separated, the unique Nash equilibrium of this stage game yields:

$$
\begin{aligned}
& X_{1 A}(T=\infty)=\max \left[\frac{a-W_{1}}{2 b}, 0\right], \\
& X_{2 A}(T=\infty)=0, \\
& X_{1 B}(T=\infty)=0, \\
& X_{2 B}(T=\infty)=\max \left[\frac{a-W_{2}}{2 b}, 0\right] .
\end{aligned}
$$

\section{Wage bargaining with complete information}

Union-firm pairs conduct simultaneous negotiations. Two assumptions are made. First, when one set of negotiations is taking place, the agents are unaware of any proposals made (or settlement reached) in related negotiations. Second, the production and market competition occur only when either both firms have come to terms with their workers or when 
one firm settles with its union and the other union decides to leave the bargaining table forever. Hence, each union-firm pair takes the decisions of its rivals as given while conducting its own negotiation. Moreover, each union-firm pair always correctly anticipates the effect of wages on the subsequent market competition.

Each negotiation proceeds as in Rubinstein's (1982) alternating-offer bargaining model. The firm and the union make alternatively wage offers, with the firm making offers in oddnumbered periods and the union making offers in even-numbered periods. The length of each period is $\Delta$. The negotiation starts in period 0 and ends when one of the negotiators accepts an offer. No limit is placed on the time that may be expended in bargaining and perpetual disagreement is a possible outcome. The union is assumed to be on strike in every period until an agreement is reached. Both the firm and the union are assumed to be impatient. The firm and the union have time preferences with constant discount rates $r_{\mathrm{f}}>0$ and $r_{\mathrm{u}}>0$, respectively. ${ }^{7}$

To capture the notion that the time it takes to come to terms is small relative to the length of the contract, we assume that the time between periods is very small. This allows a study of the limiting situations in which the bargaining procedure is essentially symmetric and the potential costs of delaying agreement by one period can be regarded as negligible. As the interval between offers and counteroffers is short and shrinks to zero, the alternating-offer model has a unique limiting subgame perfect equilibrium, which approximates the Nash bargaining solution to the bargaining problem (see Binmore, Rubinstein and Wolinsky, 1986). Thus the predicted wages are given by

$$
\begin{aligned}
& W_{1}^{\mathrm{SPE}}=\arg \max \left[U_{1}-U_{1}^{0}\right]^{\alpha} \cdot\left[\Pi_{1}-\Pi_{1}^{0}\right]^{1-\alpha} \\
& W_{2}^{\mathrm{SPE}}=\arg \max \left[U_{2}-U_{2}^{0}\right]^{\alpha} \cdot\left[\Pi_{2}-\Pi_{2}^{0}\right]^{1-\alpha}
\end{aligned}
$$

where $U_{i}^{0}=0$ and $\Pi_{i}^{0}=0$ are, respectively, the disagreement payoffs of the union and the firm. The parameter $\alpha \in(0,1)$ is the union bargaining power which is equal to $\frac{r_{\mathrm{f}}}{r_{\mathrm{u}}+r_{\mathrm{f}}}$. When markets are integrated we shall restrict our attention to the case of symmetric pure strategy equilibria associated with reciprocal intra-industry trade in which both $X_{1 B}>0$ and $X_{2 A}>0$. The necessary and sufficient condition for reciprocal intra-industry trade is $F(\alpha, T)>0$, where $F(T, \alpha)=4(2 a-T)^{2}(2-\alpha)^{2}-8\left(2 a^{2}-2 a T+5 T^{2}\right) \alpha(4-3 \alpha)$.

\footnotetext{
${ }^{7}$ Two versions of Rubinstein alternating-offer bargaining model capture different motives that induce parties to reach an agreement rather than to insist indefinitely on incompatible demands. In a first version the parties' incentive to agree lies in the fact that they are impatient : player $i$ is indifferent between receiving $x \cdot \exp \left(-r_{i} \Delta\right)$ today and $x$ tomorrow, where $r_{i}>0$ is player $i$ 's discount rate. In a second version the parties are not impatient but they face a risk that if agreement is delayed then the opportunity they hope to exploit jointly may be lost : player $i$ believes that at the end of each bargaining period there is a positive probability $1-\exp \left(-r_{i} \Delta\right)$ that the process will break down, $r_{i}>0$. So, $r_{i}$ can be interpreted either as player $i$ 's discount rate or as his estimate about the probability of a breakdown of the negotiations.
} 
Assumption 1 When markets are integrated, there is intra-industry trade in which both $X_{1 B}>0$ and $X_{2 A}>0$. That is, $F(\alpha, T)>0$.

Thus, the upper limit $\bar{T}$ such that for $T \leq \bar{T}$ there is reciprocal intra-industry trade is given by

$$
\bar{T}(\alpha)=\frac{4 a(1-\alpha)}{(2(1-\alpha)+3 \sqrt{\alpha(4-3 \alpha)})} .
$$

The assumption involves that, given tariff costs $T$, the union bargaining power is below some critical level $\widehat{\alpha}$ given by

$$
\widehat{\alpha}(T)=\frac{16 a(a-T)+22 T^{2}-6 T \sqrt{4 a(a-T)+10 T^{2}}}{16 a(a-T)+31 T^{2}} \leq 1 .
$$

Notice that as the demand parameter $a$ becomes very large, $\widehat{\alpha}$ approaches 1 . Then, the equilibrium wages and unions utilities are

$$
W_{i}^{\mathrm{SPE}}(\alpha, T)=\frac{2(2 a-T)(2-\alpha)-\sqrt{F(\alpha, T)}}{4(4-3 \alpha)}=U_{i}^{*}(\alpha, T), i=1,2 .
$$

That is,

$$
W_{i}^{\mathrm{SPE}}\left(r_{\mathrm{u}}, r_{\mathrm{f}}, T\right)=\frac{(2 a-T)\left(r_{\mathrm{f}}+2 r_{\mathrm{u}}\right)-\sqrt{G\left(r_{\mathrm{u}}, r_{\mathrm{f}}, T\right)}}{2\left(r_{\mathrm{f}}+4 r_{\mathrm{u}}\right)}=U_{i}^{*}\left(r_{\mathrm{u}}, r_{\mathrm{f}}, T\right), i=1,2,
$$

where $G\left(r_{\mathrm{u}}, r_{\mathrm{f}}, T\right)=16 a r_{\mathrm{u}}^{2}(a-T)-\left(9 r_{\mathrm{f}}^{2}+36 r_{\mathrm{f}} r_{\mathrm{u}}-4 r_{\mathrm{u}}^{2}\right) T^{2}$. Remark that $G\left(r_{\mathrm{u}}, r_{\mathrm{f}}, T\right)>0$ is the necessary and sufficient condition for reciprocal intra-industry trade when $\alpha$ is expressed in terms of $r_{\mathrm{u}}$ and $r_{\mathrm{f}}$. We obtain that

$$
\frac{\partial W_{i}^{\mathrm{SPE}}(\alpha, T)}{\partial T}>0 \Leftrightarrow T>\frac{2 a(3 \sqrt{10}(\alpha-2)-20(\alpha-1))(1-\alpha)}{5(4+\alpha(31 \alpha-44))} \equiv \widehat{T}(\alpha)
$$

We have that $\widehat{T}(\alpha)$ is decreasing with the union bargaining power $\alpha$ and $\widehat{T}(\alpha)<\bar{T}(\alpha)$. The relation between wages and the level of market integration is depicted in Figure 1 with $a=2$.

Proposition 1 If markets are weakly integrated $(T>\widehat{T}(\alpha))$ an increase in product market integration will decrease wages. However, if markets are strongly integrated $(T<\widehat{T}(\alpha))$ an increase in product market integration will increase wages.

This result is due to a tradeoff between two effects. First, when markets are integrated, each union-firm pair expects to be able to alter its relative wage position. Each unionfirm pair has an incentive to lower wages in order to gain a larger share of the product market in each country. Second, an increase in market integration induces that, for given 


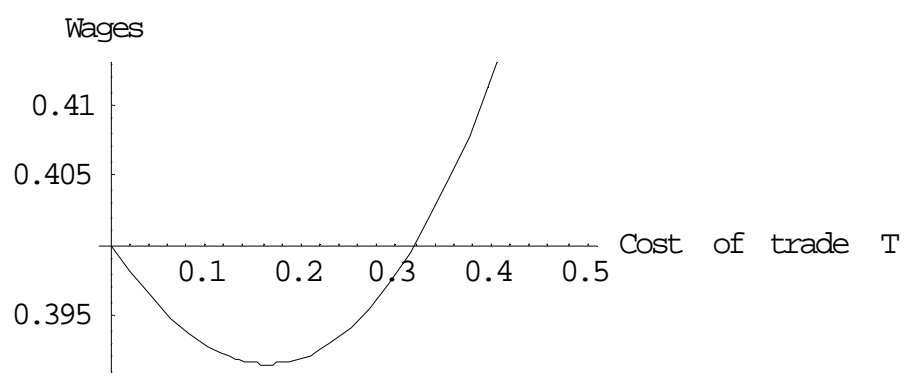

Figure 1: The relation between wages and product market integration.

wages, firms face lower costs when exporting goods, which in turn transforms into higher demand for labour. The union then exploits the higher labour demand to obtain higher wages from negotiations. Depending on the degree of market integration one effect will dominate the other one. In the appendix we show that this relationship is also observed under an alternative specification where unions maximize the surplus as in Naylor (1998). Thus, Naylor's results with a monopoly union are not robust to a right-to-manage model. Naylor (1998) has shown that, if markets are integrated, an increase in product market integration will unambiguously increase wages.

Equilibrium outputs when markets are integrated are given by

$$
\begin{aligned}
& X_{1 A}^{*}(\alpha, T)=X_{2 B}^{*}(\alpha, T)=\frac{8 a(1-\alpha)+2 T(10-7 \alpha)+\sqrt{F(\alpha, T)}}{12(4-3 \alpha) b}, \\
& X_{1 B}^{*}(\alpha, T)=X_{2 A}^{*}(\alpha, T)=\frac{8 a(1-\alpha)-T(28-22 \alpha)+\sqrt{F(\alpha, T)}}{12(4-3 \alpha) b} .
\end{aligned}
$$

Profits and prices are

$$
\Pi_{i}^{*}(\alpha, T)=\frac{(1-\alpha)\left[16 a^{2}(1-\alpha)-16 a T(1-\alpha)+2 T^{2}(38-29 \alpha)+(2 a-T) \sqrt{F(\alpha, T)}\right]}{9(4-3 \alpha) b^{2}}
$$

for $i=1,2$, and

$$
P_{i}^{*}(\alpha, T)=\frac{2 a(8-5 \alpha)+4 T(1-\alpha)+\sqrt{F(\alpha, T)}}{6(4-3 \alpha)}, i=A, B .
$$

Consumer surplus is equal to

$$
C S_{i}^{*}(\alpha, T)=\frac{(4(2 a-T)(1-\alpha)+\sqrt{F(\alpha, T)})^{2}}{72(4-3 \alpha)^{2} b}, i=A, B .
$$


The consumer surplus is increasing with an increase in product market integration.

When markets are separated, equilibrium wages and unions utilities are

$$
W_{i}^{\mathrm{SPE}}(\alpha, T=\infty)=\frac{\alpha}{2-\alpha} a=U_{i}^{*}(\alpha, T=\infty), i=1,2
$$

That is,

$$
W_{i}^{\mathrm{SPE}}\left(r_{\mathrm{u}}, r_{\mathrm{f}}, T=\infty\right)=\frac{r_{\mathrm{f}}}{r_{\mathrm{f}}+2 r_{\mathrm{u}}} a=U_{i}^{*}\left(r_{\mathrm{u}}, r_{\mathrm{f}}, T=\infty\right), i=1,2 .
$$

Equilibrium outputs when markets are separated are given by

$$
\begin{aligned}
& X_{1 A}^{*}(\alpha, T=\infty)=X_{2 B}^{*}(\alpha, T=\infty)=\frac{a}{b} \frac{(1-\alpha)}{(2-\alpha)}, \\
& X_{1 B}^{*}(\alpha, T=\infty)=X_{2 A}^{*}(\alpha, T=\infty)=0 .
\end{aligned}
$$

Profits and prices are

$$
\begin{aligned}
& \Pi_{i}^{*}(\alpha, T=\infty)=\frac{a^{2}}{b^{2}} \frac{(1-\alpha)^{2}}{(2-\alpha)}, i=1,2 . \\
& P_{i}^{*}(\alpha, T=\infty)=\frac{a}{(2-\alpha)}, i=A, B .
\end{aligned}
$$

Consumer surplus is equal to

$$
C S_{i}^{*}(\alpha, T=\infty)=\frac{(2 a(1-\alpha))^{2}}{8(2-\alpha)^{2} b}, i=A, B
$$

Comparing the situation where markets are separated $(T=\infty)$ to the one where markets are fully integrated $(T=0)$ leads to the following proposition.

Proposition 2 When separated markets become fully integrated, wages and prices will decrease while consumer surplus, profits and total quantities sold in each country will increase.

This is similar to the findings in Huizinga (1993) and Sørensen (1993). The underlying reason for this results is that firms in the two countries start to compete in a common market. This rise in the degree of competition spills over to the labour market by increasing the elasticity of labour demand. The response by the negotiators is to set a lower wage.

\section{Wage bargaining with private information}

The main feature of the negotiations is that both negotiators have private information. Each negotiator does not know the impatience (or discount rate) of the other party. It is common knowledge that the firm's discount rate is included in the set $\left[r_{\mathrm{f}}^{\mathrm{P}}, r_{\mathrm{f}}^{\mathrm{I}}\right]$, where $0<r_{\mathrm{f}}^{\mathrm{P}} \leq r_{\mathrm{f}}^{\mathrm{I}}$, and that the union's discount rate is included in the set $\left[r_{\mathrm{u}}^{\mathrm{P}}, r_{\mathrm{u}}^{\mathrm{I}}\right]$, where 
$0<r_{\mathrm{u}}^{\mathrm{P}} \leq r_{\mathrm{u}}^{\mathrm{I}}$. The superscripts "I" and "P" identify the most impatient and most patient types, respectively. The types are independently drawn from the set $\left[r_{i}^{\mathrm{P}}, r_{i}^{\mathrm{I}}\right]$ according to the probability distribution $p_{i}$, for $i=u$,f. We allow for general distributions over discount rates. This uncertainty implies bounds on the union bargaining power which are denoted by $\underline{\alpha}=r_{\mathrm{f}}^{\mathrm{P}} \cdot\left[r_{\mathrm{u}}^{\mathrm{I}}+r_{\mathrm{f}}^{\mathrm{P}}\right]^{-1}$ and $\bar{\alpha}=r_{\mathrm{f}}^{\mathrm{I}} \cdot\left[r_{\mathrm{u}}^{\mathrm{P}}+r_{\mathrm{f}}^{\mathrm{I}}\right]^{-1}$.

The next assumption imposes that, given tariff costs $T \in[0, \bar{T}]$, the upper bound on the union bargaining power is below some critical level. This assumption guarantees that, for all $T \in[0, \bar{T}]$, there is intra-industry trade $\left(X_{1 B}>0\right.$ and $\left.X_{2 A}>0\right)$ when bargaining is with private information.

Assumption $2 \bar{\alpha}<\widehat{\alpha}(T)$.

Lemma 1 Consider the wage bargaining with incomplete information in which the distributions $p_{f}$ and $p_{u}$ are common knowledge, and in which the period length shrinks to zero. Assume each union-firm pair takes the other wage settlement in the other country as given during the bargaining. For any perfect Bayesian equilibria (PBE), the payoff of the union $i$ belongs to $\left[U_{i}^{*}(\underline{\alpha}), U_{i}^{*}(\bar{\alpha})\right]$ and the payoff of the firm $i$ belongs to $\left[\Pi_{i}^{*}(\bar{\alpha}), \Pi_{i}^{*}(\underline{\alpha})\right]$.

The proof of this lemma as well as of Lemma 2 may be found in Mauleon and Vannetelbosch (2005). In Lemma $1, U_{i}^{*}(\underline{\alpha})$ and $\Pi_{i}^{*}(\underline{\alpha})$ denote, respectively, the SPE utility of the union and the SPE profit of the firm of the complete information game, when it is common knowledge that the union's bargaining power is $\alpha=\underline{\alpha}$. In case of integrated markets, then $U_{i}^{*}(\underline{\alpha})$ and $\Pi_{i}^{*}(\underline{\alpha})$ are given, respectively, by Expression (2) and Expression (3) with $\alpha=\underline{\alpha}$. In case of separated markets, then $U_{i}^{*}(\underline{\alpha})$ and $\Pi_{i}^{*}(\underline{\alpha})$ are given, respectively, by Expression (5) and Expression (6) with $\alpha=\underline{\alpha}$. Similarly for $\alpha=\bar{\alpha}$. Lemma 1 follows from Watson's (1998) analysis of Rubinstein's alternating-offer bargaining model with two-sided incomplete information. ${ }^{8}$ Lemma 1 is not a direct corollary to Watson (1998) Theorem 1 because Watson's work focuses on linear preferences, but the analysis can be modified to handle the present case. Translating Watson (1998) Theorem 2 to our framework completes the characterization of the PBE payoffs.

Lemma 2 Consider the wage bargaining with incomplete information in which the period length shrinks to zero. For any $\widetilde{U}_{i} \in\left[U_{i}^{*}(\underline{\alpha}), U_{i}^{*}(\bar{\alpha})\right], \widetilde{\Pi}_{i} \in\left[\Pi_{i}^{*}(\bar{\alpha}), \Pi_{i}^{*}(\underline{\alpha})\right]$, there exists distributions $p_{u}$ and $p_{f}$, and a PBE such that the PBE payoffs are $\widetilde{U}_{i}$ and $\widetilde{\Pi}_{i}$.

\footnotetext{
${ }^{8}$ Watson (1998) characterized the set of PBE payoffs which may arise in Rubinstein's alternating-offer bargaining game and constructed bounds (which are met) on the agreements that may be made. The bounds and the PBE payoffs set are determined by the range of incomplete information and are easy to compute because they correspond to the SPE payoffs of two bargaining games of complete information. These two games are defined by matching one player's most impatient type with the opponent's most patient type.
} 
In other words, whether or not all payoffs within the intervals given in Lemma 1 are possible depends on the distributions over types. As Watson (1998) stated, Lemma 1 and Lemma 2 establish that "each player will be no worse than he would be in equilibrium if it were common knowledge that he were his least patient type and the opponent were his most patient type. Furthermore, each player will be no better than he would be in equilibrium with the roles reversed". Since we allow for general distributions over types, multiplicity of PBE is not an exception. From Lemma 1 we obtain Proposition 3 and Proposition 4.

Proposition 3 For any distribution over types, PBE wage bargaining outcomes in case of integrated markets, $W^{*}(\underline{\alpha}, \bar{\alpha}, T)$, satisfy the following inequalities

$$
\frac{(2 a-T)\left(r_{f}^{P}+2 r_{u}^{I}\right)-\sqrt{G\left(r_{u}^{I}, r_{f}^{P}, T\right)}}{2\left(r_{f}^{P}+4 r_{u}^{I}\right)} \leq W^{*}(\underline{\alpha}, \bar{\alpha}, T) \leq \frac{(2 a-T)\left(r_{f}^{I}+2 r_{u}^{P}\right)-\sqrt{G\left(r_{u}^{P}, r_{f}^{I}, T\right)}}{2\left(r_{f}^{I}+4 r_{u}^{P}\right)} .
$$

Notice that each wage satisfying these bounds can be the outcome by choosing appropriately the distribution over types. The lower (upper) bound is the wage outcome of the complete information game, when it is common knowledge that the union's type is $r_{u}^{\mathrm{I}}$ $\left(r_{\mathrm{u}}^{\mathrm{P}}\right)$ and the firm's type is $r_{\mathrm{f}}^{\mathrm{P}}\left(r_{\mathrm{f}}^{\mathrm{I}}\right)$ (and the union bargaining power is $\underline{\alpha}(\bar{\alpha})$ ). For many distributions over types, there is a wide range of PBE: there are PBE in which the wage is close to the upper bound and there are PBE in which the wage is close to the lower bound (see below for some intuition). Expression (7) implies bounds on the firm's employment level, as well as on the firm's output, at equilibrium.

Proposition 4 For any distribution over types, PBE wage bargaining outcomes in case of separated markets, $W^{*}(\underline{\alpha}, \bar{\alpha}, T=\infty)$, satisfy the following inequalities

$$
\frac{r_{f}^{P}}{r_{f}^{P}+2 r_{u}^{I}} a \leq W^{*}(\underline{\alpha}, \bar{\alpha}, T=\infty) \leq \frac{r_{f}^{I}}{r_{f}^{I}+2 r_{u}^{P}} a .
$$

In complete information, wages will decrease and consumer surplus will increase when markets open up for competition and become fully integrated. But once the union and the firm have private information, these complete information results do not necessarily hold.

Corollary 1 In case of union-firm bargaining with private information, the wage outcome when markets are fully integrated is not necessarily smaller than the wage outcome when markets are separated. 
The necessary and sufficient condition to recover the complete information result that the wage outcome when markets are fully integrated is smaller (whatever the distribution over types) than the wage outcome when markets are separated is

$$
\underline{\alpha}>\frac{\bar{\alpha}}{2-\bar{\alpha}} \text { or } 2 r_{\mathrm{u}}^{\mathrm{P}} r_{\mathrm{f}}^{\mathrm{P}}>r_{\mathrm{u}}^{\mathrm{I}} r_{\mathrm{f}}^{\mathrm{I}} .
$$

which is obtained by comparing the lower bound from (8) with the upper bound from (7) when $T=0$. The larger the amount of private information $|\bar{\alpha}-\underline{\alpha}|$ is, the less likely the necessary and sufficient condition (9) will be satisfied. Indeed, when the amount of private information is large enough, one can always find probability distributions over types such that there is a PBE wage when markets are fully integrated which is higher than some PBE wage when markets are separated. Thus, markets opening up for competition have an ambiguous effect on wages. Nevertheless, the stronger the union is (higher $\underline{\alpha}$ ), the more likely the country's wage will decrease when markets open up for competition.

The previous analysis establishes bounds on the PBE payoffs, but it says nothing about the possible payoff vectors inside the bounds. It would be interesting to study the set of payoffs and the set of wages that are supported by perfect Bayesian equilibria in the wage bargaining game which is "close" to having complete information. Suppose there are three possible types for both the union and the firm: $r_{i}^{\mathrm{P}}, r_{i}^{*}, r_{i}^{\mathrm{I}}$ where $r_{i}^{\mathrm{P}}<r_{i}^{*}<r_{i}^{\mathrm{I}}$, for $i=u$,f. Suppose the distribution over these types $\left(r_{i}^{\mathrm{P}}, r_{i}^{*}, r_{i}^{\mathrm{I}}\right)$ is $(\beta, 1-2 \beta, \beta)$ for both the union and the firm; $\beta$ is the probability that player $i$ 's discount rate is $r_{i}^{\mathrm{P}}, 1-2 \beta$ is the probability that player $i$ 's discount rate is $r_{i}^{*}$, and $\beta$ is the probability that player $i$ 's discount rate is $r_{i}^{\mathrm{I}}$. Then, we might wish to know how the set of PBE payoffs or the wage outcomes change as $\beta$ converges to zero, where there is only a slight chance that player $i$ is either of type $r_{i}^{\mathrm{P}}$ or type $r_{i}^{\mathrm{T}}$. From Watson's (1998) Theorem 4 and Theorem 5 , it follows that, as $\beta$ converges to zero, PBE wage outcomes satisfy the bounds in Expression (7) and Expression (8) with $r_{i}^{\mathrm{P}}=r_{i}^{*}$. There are PBE in which the wage is close to the upper bound $W^{\mathrm{SPE}}\left(r_{\mathrm{u}}^{*}, r_{\mathrm{f}}^{\mathrm{I}}\right)$ and there are PBE in which the wage is close to the lower bound $W^{\mathrm{SPE}}\left(r_{\mathrm{u}}^{\mathrm{I}}, r_{\mathrm{f}}^{*}\right)$. Thus, PBE wages do not converge to a single wage, despite that the distribution over types converges to a point mass distribution. ${ }^{9}$

\footnotetext{
${ }^{9}$ This lopsided convergence follows from the construction of PBE strategies, where players will punish one another if they depart from their equilibrium strategies. An effective form of punishment in the bargaining game is that when a player takes some deviant action, beliefs about him are updated optimistically -putting probability one on his weakest type. The existence of a very impatient type (a type near $r_{i}^{\mathrm{I}}$ as compared to $r_{i}^{*}$ ) allows the threat of such a revision of beliefs, however small is the probability of the impatient type. The existence of a very patient type has little effect, since it would not be used in punishing a player.
} 


\section{Maximal delay in reaching an agreement}

Inefficient outcomes are possible, even as the period length shrinks to zero. While the scope of possible inefficiency is clear from Lemma 1 and Lemma 2, what is not so obvious is the potential for delay. The wage bargaining game may involve delay (strikes or lock-outs), but not perpetual disagreement, at equilibrium (see Watson, 1998). ${ }^{10}$ In fact, delay is positively related to the distance between the discount rates of the most and least patient types of the players. If the range of types is reduced, then this leads to a smaller range of possible payoffs and less delay. Delay can occur even when the game is close to one of complete information (as the type distributions converge to point mass distributions).

We propose to identify strike activity with the maximum delay time in reaching an agreement. Only in average this measure is a good proxy for actual strike duration. ${ }^{11}$ It is not uncommon in the literature on bargaining to analyze the maximum number of delay time that may be expended before reaching an agreement. ${ }^{12}$ In the appendix we compute the maximum delay in equilibrium which shows that an agreement is reached in finite time and that delay time equals zero as incomplete information vanishes (in that $r_{i}^{\mathrm{P}}$ and $r_{i}^{\mathrm{T}}$ converge).

In case of integrated markets, the maximum real delay time in reaching an agreement is given by

$$
D(T)=\min \left\{D^{\mathrm{u}}(T), D^{\mathrm{f}}(T)\right\}
$$

\footnotetext{
${ }^{10}$ Watson (1998) has constructed equilibria with delay in which the types of each player behave identically (no information is revealed in equilibrium), players use pure strategies, and players make non-serious offers until some appointed date.

${ }^{11}$ In the literature on strikes, three different measures of strike activity are usually proposed: the strike incidence, the strike duration, and the number of work days lost due to work stoppages. See Cheung and Davidson (1991), Kennan and Wilson (1989). Since we allow for general distributions over types and we may have a multiplicity of PBE, we are unable to compute measures of strike activity as the ones just mentioned.

${ }^{12}$ Cramton (1992) has constructed a sequential equilibrium in a bargaining model with two-sided uncertainty, where types are revealed after a maximum of two rounds, but where delay is directly related to the types of the players. There is also a continuum of other sequential equilibria where types are not fully revealed. Unlike in Rubinstein's model in which the time between offers is fixed, in Cramton (1992) each player can delay making offers. This ability to delay offers enables each player to commit to not revising or rescinding an offer until a counter-offer is made. Cai (2003) has also analyzed the maximum number of delay periods but in a multilateral bargaining. His model has a finite number of Markov perfect equilibria, some of which exhibiting wasteful delays. The maximum number of delay periods that can be supported in Markov perfect equilibria increases in the order of the square of the number of players. These results are robust to a relaxing of the Markov requirements and to more general surplus functions. Ausubel, Cramton and Deneckere (2002) provide a recent survey of bargaining models with incomplete information.
} 
where

$$
D^{\mathrm{u}}(T)=-\frac{1}{r_{\mathrm{u}}^{\mathrm{P}}} \cdot \log \left[\left(\frac{4 r_{\mathrm{u}}^{\mathrm{P}}+r_{\mathrm{f}}^{\mathrm{I}}}{4 r_{\mathrm{u}}^{\mathrm{I}}+r_{\mathrm{f}}^{\mathrm{P}}}\right) \frac{(2 a-T)\left(r_{\mathrm{f}}^{\mathrm{P}}+2 r_{\mathrm{u}}^{\mathrm{I}}\right)-\sqrt{G\left(r_{\mathrm{u}}^{\mathrm{I}}, r_{\mathrm{f}}^{\mathrm{P}}, T\right)}}{(2 a-T)\left(r_{\mathrm{f}}^{\mathrm{I}}+2 r_{\mathrm{u}}^{\mathrm{P}}\right)-\sqrt{G\left(r_{\mathrm{u}}^{\mathrm{P}}, r_{\mathrm{f}}^{\mathrm{I}}, T\right)}}\right]
$$

is the maximum real time the union would spend negotiating, and

$$
\begin{aligned}
D^{\mathrm{f}}(T)= & -\frac{1}{r_{\mathrm{f}}^{\mathrm{P}}} \cdot \log \left[\left(\frac{r_{\mathrm{u}}^{\mathrm{P}}}{r_{\mathrm{u}}^{\mathrm{I}}}\right)\left(\frac{4 r_{\mathrm{u}}^{\mathrm{I}}+r_{\mathrm{f}}^{\mathrm{P}}}{4 r_{\mathrm{u}}^{\mathrm{P}}+r_{\mathrm{f}}^{\mathrm{I}}}\right)^{2} \cdot\right. \\
& \left.\frac{8 a(a-T) r_{\mathrm{u}}^{\mathrm{P}}+\left(9 r_{\mathrm{f}}^{\mathrm{I}}+38 r_{\mathrm{u}}^{\mathrm{P}}\right) T^{2}+(2 a-T) \sqrt{G\left(r_{\mathrm{u}}^{\mathrm{P}}, r_{\mathrm{f}}^{\mathrm{I}}, T\right)}}{8 a(a-T) r_{\mathrm{u}}^{\mathrm{I}}+\left(9 r_{\mathrm{f}}^{\mathrm{P}}+38 r_{\mathrm{u}}^{\mathrm{I}}\right) T^{2}+(2 a-T) \sqrt{G\left(r_{\mathrm{u}}^{\mathrm{I}}, r_{\mathrm{f}}^{\mathrm{P}}, T\right)}}\right]
\end{aligned}
$$

is the maximum real time the firm would spend negotiating. In fact, $D^{\mathrm{u}}(T)\left(D^{\mathrm{f}}(T)\right)$ is the maximum real time the union (firm) would spend negotiating in any equilibrium if the union (firm) was of its most patient type. So, $D^{\mathrm{u}}(T)\left(D^{\mathrm{f}}(T)\right)$ is the upper bound on the maximum time the union (firm) of type $r_{\mathrm{u}}\left(r_{f}\right)$ would spend negotiating; maximum time that is decreasing with type $r_{\mathrm{u}}\left(r_{\mathrm{f}}\right)$. So, the more patient a player is the greater the delay that may be observed. Since $D^{\mathrm{u}}(T)$ and $D^{\mathrm{f}}(T)$ are positive, finite numbers, the maximum real delay in reaching an agreement in case of integrated markets is finite and converges to zero as $r_{i}^{\mathrm{I}}$ and $r_{i}^{\mathrm{P}}$ become close, for $i=\mathrm{u}$,f. In the appendix we show that

$$
\frac{\partial D^{\mathrm{u}}(T)}{\partial T}>0 \text { and } \frac{\partial D^{\mathrm{f}}(T)}{\partial T}>0 .
$$

Proposition 5 From an initial situation of reciprocal intra-industry trade (i.e. markets are integrated), an increase in product market integration will decrease the maximal delay in reaching an agreement.

When markets are integrated, each union-firm pair expects to be able to alter its relative wage position. That is, each union-firm pair has an incentive to lower wages in order to gain a larger share of the product market in each country. This incentive is stronger the more integrated the markets are since now a wage decrease makes the unionfirm pair winning a more substantial market share of its rival. This explain why it is likely that more concessions and less conflicts in wage negotiations would occur once markets become more integrated.

In case of separated markets, the maximum real delay time in reaching an agreement is given by

$$
D(T=\infty)=\min \left\{D^{\mathrm{u}}(T=\infty), D^{\mathrm{f}}(T=\infty)\right\}
$$

where

$$
D^{\mathrm{u}}(T=\infty)=-\frac{1}{r_{\mathrm{u}}^{\mathrm{P}}} \cdot \log \left[\left(\frac{2 r_{\mathrm{u}}^{\mathrm{P}}+r_{\mathrm{f}}^{\mathrm{I}}}{2 r_{\mathrm{u}}^{\mathrm{I}}+r_{\mathrm{f}}^{\mathrm{P}}}\right)\left(\frac{r_{\mathrm{f}}^{\mathrm{P}}}{r_{\mathrm{f}}^{\mathrm{I}}}\right)\right]
$$


is the maximum real time the union would spend negotiating, and

$$
D^{\mathrm{f}}(T=\infty)=-\frac{1}{r_{\mathrm{f}}^{\mathrm{P}}} \cdot \log \left[\left(\frac{2 r_{\mathrm{u}}^{\mathrm{I}}+r_{\mathrm{f}}^{\mathrm{P}}}{2 r_{\mathrm{u}}^{\mathrm{P}}+r_{\mathrm{f}}^{\mathrm{T}}}\right)^{2}\left(\frac{r_{\mathrm{u}}^{\mathrm{P}}}{r_{\mathrm{u}}^{\mathrm{T}}}\right)^{2}\right]
$$

is the maximum real time the firm would spend negotiating. Since $D^{\mathrm{u}}(T=\infty)$ and $D^{\mathrm{f}}(T=\infty)$ are positive, finite numbers, the maximum real delay in reaching an agreement in case of separated markets is finite and converges to zero as $r_{i}^{\mathrm{I}}$ and $r_{i}^{\mathrm{P}}$ become close, for $i=\mathrm{u}, \mathrm{f}$.

Let us compare the strike activity when markets go from separated markets to fully integrated markets. We have $D^{\mathrm{u}}(T=0)>D^{\mathrm{u}}(T=\infty)$. The maximum real time the union would spend negotiating is shorter when markets are separated. However, we have $D^{\mathrm{f}}(T=0)<D^{\mathrm{f}}(T=\infty)$. The maximum real time the firm would spend negotiating is shorter when markets are fully integrated. Let us assume that $r_{u}^{\mathrm{P}}=r_{\mathrm{f}}^{\mathrm{P}}=r^{\mathrm{P}}$ and $r_{\mathrm{u}}^{\mathrm{I}}=r_{\mathrm{f}}^{\mathrm{I}}=r^{\mathrm{I}}$. Then,

$$
D(T=\infty)>D(T=0) \Leftrightarrow D^{\mathrm{u}}(T=\infty)>D^{\mathrm{f}}(T=0) \Leftrightarrow 22 r^{\mathrm{P}} r^{\mathrm{I}}-\left(r^{\mathrm{P}}\right)^{2}-\left(r^{\mathrm{I}}\right)^{2}>0 .
$$

For instance, when $r^{\mathrm{P}}=0.01$ and $r^{\mathrm{I}}=0.1$ we have $D^{\mathrm{u}}(T=\infty)>D^{\mathrm{f}}(T=0)$, but when $r^{\mathrm{P}}=0.001$ and $r^{\mathrm{I}}=0.1$ we have $D^{\mathrm{u}}(T=\infty)<D^{\mathrm{f}}(T=0)$. Thus, the possibility of being of a very patient type (i.e. a relatively strong negotiator) makes strikes more likely when markets open up for competition and become fully integrated.

Thus, markets opening up for competition have an ambiguous effect on the maximum real delay time in reaching an agreement. When markets become open, each union-firm pair has a stronger incentive to lower wages and to concede earlier in order to gain a larger share of the product market in each country. However, markets opening up raise the potential payoffs for the union and the firm, and in expanding the payoff set (or range of possible payoffs), also increase the scope for delay (longer strikes and lockouts may be needed for screening the private information).

We provide now an example about the maximum delay. In this example we let $r_{\mathrm{f}}^{\mathrm{P}}=$ $r_{\mathrm{u}}^{\mathrm{P}}=r^{\mathrm{P}}, r_{\mathrm{f}}^{\mathrm{I}}=r_{\mathrm{u}}^{\mathrm{I}}=r^{\mathrm{I}}, r^{\mathrm{I}}=0.33-r^{\mathrm{P}}$ with $r^{\mathrm{P}} \in[0.04,0.16]$ and $a=2$. Table 1 gives us the integer part of the maximum delay for different values of the parameter $T .^{13}$ We observe that (i) $D^{\mathrm{u}}$ and $D^{\mathrm{f}}$ are increasing with the amount of private information $\left|r_{i}^{\mathrm{P}}-r_{i}^{\mathrm{T}}\right|$, (ii) $D^{\mathrm{u}}$ and $D^{f}$ are slightly increasing with $T$ for $T \leq \bar{T}$. Notice that real delay time in reaching an agreement is not negligible: many bargaining rounds may be needed at equilibrium before an agreement is reached. Results (i) and (ii) hold in general.

\footnotetext{
${ }^{13}$ We can interpret $r_{i}$ as the annual discount rate and the numbers in Table 1 as the maximum number of days needed to reach an agreement. Indeed, the integer part of the maximum delays for $\Delta=1 / 365$ are exactly the numbers of Table 1 . The data in Table 1 seem consistent with U.S. strike durations reported in Cramton and Tracy (1994).
} 


\begin{tabular}{|c|r|r|r|r|r|r|r|r|r|r|}
\cline { 2 - 10 } \multicolumn{1}{c|}{} & \multicolumn{2}{c|}{$T=0$} & \multicolumn{2}{c|}{$T=\frac{1}{8}$} & \multicolumn{2}{c|}{$T=\frac{1}{4}$} & \multicolumn{2}{c|}{$T=\frac{1}{2}$} & \multicolumn{2}{c|}{$T=\infty$} \\
\hline$r^{\mathrm{P}}$ & $D^{\mathrm{u}}$ & $D^{\mathrm{f}}$ & $D^{\mathrm{u}}$ & $D^{\mathrm{f}}$ & $D^{\mathrm{u}}$ & $D^{\mathrm{f}}$ & $D^{\mathrm{u}}$ & $D^{\mathrm{f}}$ & $D^{\mathrm{u}}$ & $D^{\mathrm{f}}$ \\
\hline 0.16 & 0 & 0 & 0 & 0 & 0 & 0 & 0 & 0 & 0 & 0 \\
0.15 & 1 & 0 & 1 & 0 & 1 & 0 & 2 & 1 & 1 & 1 \\
0.14 & 3 & 1 & 3 & 1 & 3 & 1 & 3 & 1 & 2 & 2 \\
0.13 & 5 & 2 & 5 & 2 & 5 & 2 & 5 & 2 & 4 & 4 \\
0.12 & 7 & 3 & 7 & 3 & 7 & 3 & 7 & 4 & 6 & 6 \\
0.11 & 9 & 5 & 10 & 5 & 10 & 5 & 10 & 5 & 8 & 8 \\
0.10 & 13 & 7 & 13 & 7 & 13 & 7 & 14 & 7 & 10 & 11 \\
0.09 & 17 & 9 & 17 & 9 & 17 & 9 & 19 & 10 & 14 & 15 \\
0.08 & 22 & 12 & 22 & 12 & 22 & 12 & - & - & 18 & 19 \\
0.07 & 29 & 16 & 29 & 17 & 29 & 17 & - & - & 24 & 26 \\
0.06 & 38 & 23 & 38 & 23 & 39 & 24 & - & - & 32 & 35 \\
0.05 & 52 & 33 & 52 & 33 & 53 & 35 & - & - & 43 & 49 \\
0.04 & 74 & 50 & 74 & 50 & 76 & 55 & - & - & 62 & 73 \\
\hline
\end{tabular}

Table 1: Maximum delay in reaching an agreement

\section{Conclusion}

We have considered a two-country model of wage determination with private information in unionized imperfectly competitive industries. We have investigated the effects of separated product markets opening up for competition as well as of further market integration on the negotiated wage and the maximum delay in reaching an agreement. From an initial situation of reciprocal intra-industry trade, an increase in product market integration will decrease the maximal delay in reaching an agreement. However, markets opening up for competition have an ambiguous effect on both the wage outcome and the maximum real delay time in reaching an agreement.

Thus, contrary to the results found in the literature with complete information, we have shown that, in presence of private information, a reduction in fixed costs (the fact that product markets open up for competition) has an ambiguous impact on the negotiated wage. So, our model suggests that one should be cautious when making policy recommendations with respect to the impact of product market integration on wages and employment levels. Nevertheless, this ambiguity does not prevent us to draw very interesting results. Indeed, we have shown that the stronger the union is, the more likely the country's wage will decrease when markets open up for competition. Finally, notice that the possibility of being of a very patient type (i.e. a relatively strong negotiator) makes 
strikes more likely when markets open up for competition.

\section{Acknowledgments}

We wish to thank Pierre Picard for valuable comments. Financial support from Spanish Ministerio de Ciencia y Tecnología under the project BEC 2003-02084, support of a SSTC grant from the Belgian Federal government under the IAP contract 5/26 (FUSL), and support from the Belgian French Community's program Action de Recherches Concertée 03/08-302 (UCL) are gratefully acknowledged.

This paper presents research results of the Belgian Program on Interuniversity Poles of Attraction initiated by the Belgian State, Prime Minister's Office, Science Policy Programming.

\section{Appendix}

\section{A Unions maximizing economic rents}

Suppose that each firm is unionized and each union maximizes its economic rents. Hence, $U_{1}=L_{1}\left(W_{1}, W_{2}\right) \cdot W_{1}$ and $U_{2}=L_{2}\left(W_{1}, W_{2}\right) \cdot W_{2}$. In order to get a closed form solution from the wage bargaining we need to fix the union bargaining power. For instance, let assume that the firm and the union have equal bargaining power: $\alpha=\frac{1}{2}$. Then, we obtain that the equilibrium wage outcome is

$$
W_{i}^{\mathrm{SPE}}\left(T, \alpha=\frac{1}{2}\right)=\frac{1}{14}\left(10 a-5 T-\frac{16 a^{2}-16 a T-59 T^{2}}{\sqrt[3]{Z}}-\sqrt[3]{Z}\right), i=1,2
$$

where

$Z=64 a^{3}-96 a^{2} T+552 a T^{2}-260 T^{3}+21 T \sqrt{256 a^{4}-512 a^{3} T+528 a^{2} T^{2}-272 a T^{3}+619 T^{4}}$. The relation between wages and the level of market integration is very close to the one obtained assuming that unions maximize wages and is depicted in Figure 2 with $a=2$.

\section{B Maximal delay}

The negotiation proceeds as in Rubinstein's (1982) alternating-offer bargaining model. The firm and the union make alternatively wage offers, with the firm making offers in oddnumbered periods and the union making offers in even-numbered periods. The negotiation starts in period 0 and ends when one of the negotiators accepts an offer. No limit is placed 


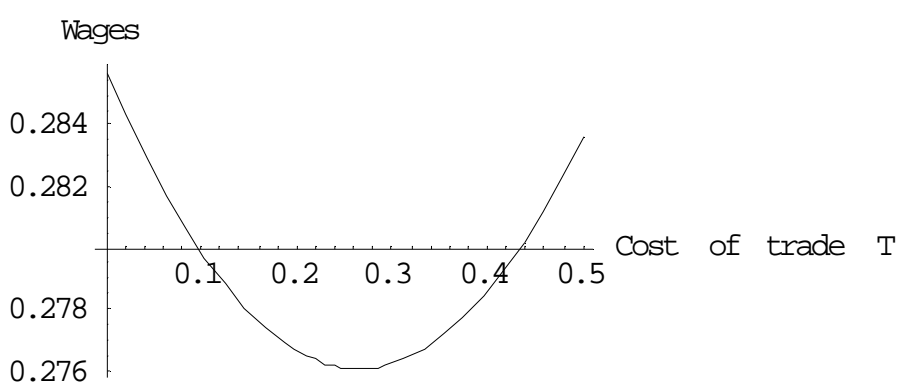

Figure 2: Unions maximizing rents and $\alpha=\frac{1}{2}$.

on the time that may be expended in bargaining and perpetual disagreement is a possible outcome. The union is assumed to be on strike in every period until an agreement is reached. Both the firm and the union are assumed to be impatient. The firm and the union have time preferences with constant discount factors $\delta_{f} \in(0,1)$ and $\delta_{\mathrm{u}} \in(0,1)$, respectively. It is assumed that each union-firm pair takes the other wage settlement as given during the negotiation. For any wage bargaining which leads to an agreement $W_{i}$ at period $n, \delta_{\mathrm{f}}^{n} \cdot \Pi_{i}\left(W_{i}, L_{i}\left(W_{i}, W_{j}\right)\right)$ and $\delta_{\mathrm{u}}^{n} \cdot U\left(W_{i}, L_{i}\left(W_{i}, W_{j}\right)\right)$ are, respectively, firm $i$ 's payoff and union $i$ 's payoff. For any wage bargaining which leads to perpetual disagreement, disagreement payoffs are set to zero.

From Binmore, Rubinstein and Wolinsky (1986), the SPE wage outcome is such that

$$
\left\{\begin{array}{l}
\Pi_{i}\left(T, W_{i \mathrm{u}}, L_{i}\left(W_{i \mathrm{u}}, W_{j}\right)\right)=\delta_{\mathrm{f}} \cdot \Pi_{i}\left(T, W_{i \mathrm{f}}, L_{i}\left(W_{i \mathrm{f}}, W_{j}\right)\right) \\
U_{i}\left(T, W_{i \mathrm{f}}, L_{i}\left(W_{i \mathrm{f}}, W_{j}\right)\right)=\delta_{\mathrm{u}} \cdot U\left(T, W_{i \mathrm{u}}, L_{i}\left(W_{i \mathrm{u}}, W_{j}\right)\right)
\end{array}\right.
$$

where $W_{i \text { u }}$ is the SPE wage outcome if the union makes the first wage offer, and $W_{i f}$ is the SPE wage outcome if the firm makes the first offer. Let $H\left(T, \delta_{\mathrm{u}}, \delta_{\mathrm{f}}\right)=4\left(1+\delta_{\mathrm{f}}-\right.$ $\left.2 \delta_{\mathrm{f}} \delta_{\mathrm{u}}\right)^{2}(2 a-T)^{2}-8\left(1-\delta_{\mathrm{f}}\right)\left(\left(1-\delta_{\mathrm{f}}\left(1-\delta_{\mathrm{u}}\right)^{2}\right)\left(2 a^{2}-2 a T+5 T^{2}\right)\right.$. Since the union makes the first offer, the unique symmetric SPE wages in case of integrated markets are given by

$$
W_{i}^{\mathrm{SPE}}\left(T, \delta_{\mathrm{u}}, \delta_{f}\right)=\frac{2\left(1+\delta_{\mathrm{f}}\left(1-2 \delta_{\mathrm{u}}\right)\right)(2 a-T)-\sqrt{H\left(T, \delta_{\mathrm{u}}, \delta_{f}\right)}}{4\left(1-\delta_{\mathrm{f}}\left(1-2 \delta_{\mathrm{u}}\right)^{2}\right)}, i=1,2,
$$

from which we get the SPE profits and the SPE unions payoffs,

$$
\begin{aligned}
U_{i}^{*}\left(T, \delta_{\mathrm{u}}, \delta_{f}\right)= & \frac{2\left(1+\delta_{\mathrm{f}}\left(1-2 \delta_{\mathrm{u}}\right)\right)(2 a-T)-\sqrt{H\left(T, \delta_{\mathrm{u}}, \delta_{f}\right)}}{4\left(1-\delta_{\mathrm{f}}\left(1-2 \delta_{\mathrm{u}}\right)^{2}\right)}, i=1,2, \\
\Pi_{i}^{*}\left(T, \delta_{\mathrm{u}}, \delta_{\mathrm{f}}\right)= & \frac{\delta_{\mathrm{f}}\left(1-\delta_{\mathrm{u}}\right)}{9 b\left(1-\delta_{\mathrm{f}}\left(1-2 \delta_{u}\right)^{2}\right)^{2}}\left[2 \left(4 a^{2}\left(1+\delta_{f}\left(1-2 \delta_{u}\right)^{2}\right)\left(1-\delta_{u}\right)(a-T)+(1+\right.\right. \\
& \left.\left.\left.8 \delta_{u}+\delta_{f}\left(1-2 \delta_{u}\right)^{2}\left(1-10 \delta_{u}\right)\right) T^{2}\right)-\left(1-2 \delta_{u}\right)(2 a-T) \sqrt{H\left(T, \delta_{\mathrm{u}}, \delta_{f}\right)}\right] .
\end{aligned}
$$


Similarly, the unique symmetric SPE wages in case of separated markets are given by

$$
\left\{\begin{array}{l}
\Pi_{i}\left(T=\infty, W_{i \mathrm{u}}, L_{i}\left(W_{i \mathrm{u}}, W_{j}\right)\right)=\delta_{\mathrm{f}} \cdot \Pi_{i}\left(T=\infty, W_{i \mathrm{f}}, L_{i}\left(W_{i \mathrm{f}}, W_{j}\right)\right) \\
U_{i}\left(T=\infty, W_{i \mathrm{f}}, L_{i}\left(W_{i \mathrm{f}}, W_{j}\right)\right)=\delta_{\mathrm{u}} \cdot U\left(T=\infty, W_{i \mathrm{u}}, L_{i}\left(W_{i \mathrm{u}}, W_{j}\right)\right)
\end{array}\right.
$$

where $W_{i u}$ is the SPE wage outcome if the union makes the first wage offer, and $W_{i f}$ is the SPE wage outcome if the firm makes the first offer. Since the union makes the first offer, the SPE wage is

$$
W_{\mathrm{i}}^{\mathrm{SPE}}\left(T=\infty, \delta_{\mathrm{u}}, \delta_{\mathrm{f}}\right)=\frac{1-\sqrt{\delta_{\mathrm{f}}}}{1-\sqrt{\delta_{\mathrm{f}}} \delta_{\mathrm{u}}} a, i=1,2,
$$

from which we get the SPE profits and the SPE unions payoffs,

$$
\begin{aligned}
& U_{i}^{*}\left(T=\infty, \delta_{\mathrm{u}}, \delta_{\mathrm{f}}\right)=\frac{\left(1-\sqrt{\delta_{\mathrm{f}}}\right) a}{1-\sqrt{\delta_{\mathrm{f}}} \delta_{\mathrm{u}}}, i=1,2, \\
& \Pi_{i}^{*}\left(T=\infty, \delta_{\mathrm{u}}, \delta_{\mathrm{f}}\right)=\frac{\delta_{\mathrm{f}}\left(1-\delta_{\mathrm{u}}\right)^{2} a^{2}}{4\left(1-\sqrt{\delta_{\mathrm{f}}} \delta_{\mathrm{u}}\right)^{2} b}, i=1,2 .
\end{aligned}
$$

The players have private information. They are uncertain about each others' discount factors. Player $i$ 's discount factor is included in the set $\left[\delta_{i}^{\mathrm{I}}, \delta_{i}^{\mathrm{P}}\right]$, where $0<\delta_{i}^{\mathrm{I}} \leq \delta_{i}^{\mathrm{P}}<1$, for $i=$ u,f. We allow for general probability distributions over discount factors. From Watson (1998), we have that: (i) in case of integrated markets, for any PBE, the payoff of the union belongs to $\left[U_{i}^{*}\left(T, \delta_{\mathrm{u}}^{\mathrm{I}}, \delta_{\mathrm{f}}^{\mathrm{P}}\right), U_{i}^{*}\left(T, \delta_{\mathrm{u}}^{\mathrm{P}}, \delta_{\mathrm{f}}^{\mathrm{I}}\right)\right]$ and the payoff of the firm belongs to $\left[\Pi_{i}^{*}\left(T, \delta_{\mathrm{u}}^{\mathrm{P}}, \delta_{\mathrm{f}}^{\mathrm{T}}\right), \Pi_{i}^{*}\left(T, \delta_{\mathrm{u}}^{\mathrm{T}}, \delta_{\mathrm{f}}^{\mathrm{P}}\right)\right]$; (ii) in case of separated markets, for any PBE, the payoff of the union belongs to $\left[U_{i}^{*}\left(T=\infty, \delta_{u}^{\mathrm{I}}, \delta_{\mathrm{f}}^{\mathrm{P}}\right), U_{i}^{*}\left(T=\infty, \delta_{\mathrm{u}}^{\mathrm{P}}, \delta_{\mathrm{f}}^{\mathrm{I}}\right)\right]$ and the payoff of the firm belongs to $\left[\Pi_{i}^{*}\left(T=\infty, \delta_{\mathrm{u}}^{\mathrm{P}}, \delta_{\mathrm{f}}^{\mathrm{I}}\right), \Pi_{i}^{*}\left(T=\infty, \delta_{\mathrm{u}}^{\mathrm{I}}, \delta_{\mathrm{f}}^{\mathrm{P}}\right)\right]$.

In case of integrated markets, the maximum number of bargaining periods the union would spend negotiating, $I\left(m^{\mathrm{u}}(T)\right)$, is given by

$$
U_{i}^{*}\left(T, \delta_{\mathrm{u}}^{\mathrm{I}}, \delta_{\mathrm{f}}^{\mathrm{P}}\right)=\left(\delta_{\mathrm{u}}^{\mathrm{P}}\right)^{m^{\mathrm{u}}(T)} \cdot U_{i}^{*}\left(T, \delta_{\mathrm{u}}^{\mathrm{P}}, \delta_{\mathrm{f}}^{\mathrm{I}}\right),
$$

from which we obtain

$m^{\mathrm{u}}(T)=\frac{1}{\log \left(\delta_{\mathrm{u}}^{\mathrm{P}}\right)} \cdot \log \left[\frac{2\left(1+\delta_{\mathrm{f}}^{\mathrm{P}}\left(1-2 \delta_{\mathrm{u}}^{\mathrm{I}}\right)\right)(2 a-T)-\sqrt{H\left(T, \delta_{\mathrm{u}}^{\mathrm{I}}, \delta_{\mathrm{f}}^{\mathrm{P}}\right)}}{2\left(1+\delta_{\mathrm{f}}^{\mathrm{I}}\left(1-2 \delta_{\mathrm{u}}^{\mathrm{P}}\right)\right)(2 a-T)-\sqrt{H\left(T, \delta_{\mathrm{u}}^{\mathrm{P}}, \delta_{\mathrm{f}}^{\mathrm{I}}\right)}} \frac{\left(1-\delta_{\mathrm{f}}^{\mathrm{I}}\left(1-2 \delta_{\mathrm{u}}^{\mathrm{P}}\right)^{2}\right)}{\left(1-\delta_{\mathrm{f}}^{\mathrm{P}}\left(1-2 \delta_{\mathrm{u}}^{\mathrm{I}}\right)^{2}\right)}\right]$.

Notice that $I\left(m^{\mathrm{u}}(T)\right)$ is simply the integer part of $m^{\mathrm{u}}(T)$. It is customary to express the players' discount factors in terms of discount rates, $r_{\mathrm{u}}$ and $r_{\mathrm{f}}$, and the length of the bargaining period, $\Delta$, according to formula $\delta_{i}=\exp \left(-r_{i} \Delta\right)$, for $i=$ u,f. With this interpretation, player $i$ 's type is identified with his discount rate $r_{i}$, where $r_{i} \in\left[r_{i}^{\mathrm{P}}, r_{i}^{\mathrm{I}}\right]$. We thus have that $\delta_{i}^{\mathrm{I}}=\exp \left(-r_{i}^{\mathrm{I}} \Delta\right)$ and $\delta_{i}^{\mathrm{P}}=\exp \left(-r_{i}^{\mathrm{P}} \Delta\right)$, for $i=$ u,f. Note that $r_{i}^{\mathrm{I}} \geq r_{i}^{\mathrm{P}}$ since greater patience implies a lower discount rate. As $\Delta$ approaches zero, we have (using l'Hopital's rule): (i) $\left(1-\delta_{\mathrm{f}}^{\mathrm{I}}\left(1-2 \delta_{\mathrm{u}}^{\mathrm{P}}\right)^{2}\right) /\left(1-\delta_{\mathrm{f}}^{\mathrm{P}}\left(1-2 \delta_{\mathrm{u}}^{\mathrm{I}}\right)^{2}\right)$ converges to $\left(4 r_{\mathrm{u}}^{\mathrm{P}}+r_{\mathrm{f}}^{\mathrm{I}}\right) /\left(4 r_{\mathrm{u}}^{\mathrm{I}}+r_{\mathrm{f}}^{\mathrm{P}}\right)$, 
(ii) $\left(2\left(1+\delta_{\mathrm{f}}^{\mathrm{P}}\left(1-2 \delta_{\mathrm{u}}^{\mathrm{I}}\right)\right)(2 a-T)-\sqrt{H\left(T, \delta_{\mathrm{u}}^{\mathrm{I}}, \delta_{\mathrm{f}}^{\mathrm{P}}\right)}\right) /\left(2\left(1+\delta_{\mathrm{f}}^{\mathrm{I}}\left(1-2 \delta_{\mathrm{u}}^{\mathrm{P}}\right)\right)(2 a-T)-\sqrt{H\left(T, \delta_{\mathrm{u}}^{\mathrm{P}}, \delta_{\mathrm{f}}^{\mathrm{I}}\right)}\right)$ converges to $\left((2 a-T)\left(r_{\mathrm{f}}^{\mathrm{P}}+2 r_{\mathrm{u}}^{\mathrm{I}}\right)-\sqrt{G\left(r_{\mathrm{u}}^{\mathrm{I}}, r_{\mathrm{f}}^{\mathrm{P}}, T\right)}\right) /\left((2 a-T)\left(r_{\mathrm{f}}^{\mathrm{I}}+2 r_{\mathrm{u}}^{\mathrm{P}}\right)-\sqrt{G\left(r_{\mathrm{u}}^{\mathrm{P}}, r_{\mathrm{f}}^{\mathrm{I}}, T\right)}\right)$, and (iii) $\Delta / \log \left(\delta_{\mathrm{u}}^{\mathrm{P}}\right)$ converges to $\left(-1 / r_{\mathrm{u}}^{\mathrm{P}}\right)$. These facts imply that

$D^{\mathrm{u}}(T)=\lim _{\Delta \rightarrow \mathbf{0}}\left(m^{\mathrm{u}}(T) \cdot \Delta\right)=-\frac{1}{r_{\mathrm{u}}^{\mathrm{P}}} \cdot \log \left[\left(\frac{4 r_{\mathrm{u}}^{\mathrm{P}}+r_{\mathrm{f}}^{\mathrm{I}}}{4 r_{\mathrm{u}}^{\mathrm{I}}+r_{\mathrm{f}}^{\mathrm{P}}}\right) \frac{(2 a-T)\left(r_{\mathrm{f}}^{\mathrm{P}}+2 r_{\mathrm{u}}^{\mathrm{I}}\right)-\sqrt{G\left(r_{\mathrm{u}}^{\mathrm{I}}, r_{\mathrm{f}}^{\mathrm{P}}, T\right)}}{(2 a-T)\left(r_{\mathrm{f}}^{\mathrm{I}}+2 r_{\mathrm{u}}^{\mathrm{P}}\right)-\sqrt{G\left(r_{\mathrm{u}}^{\mathrm{P}}, r_{\mathrm{f}}^{\mathrm{I}}, T\right)}}\right]$,

which is a positive, finite number. Notice that $D^{\mathrm{u}}(T)$ converges to zero as $r_{i}^{\mathrm{P}}$ and $r_{i}^{\mathrm{I}}$ become close, for $i=\mathrm{u}, \mathrm{f}$. We have

$$
\frac{\partial D^{\mathrm{u}}(T)}{\partial T}=\frac{9 a T}{r_{\mathrm{u}}^{\mathrm{P}}\left(2 a^{2}-2 a T+5 T^{2}\right)}\left(-\frac{r_{\mathrm{f}}^{\mathrm{P}}+2 r_{\mathrm{u}}^{\mathrm{I}}}{\sqrt{G\left(r_{\mathrm{u}}^{\mathrm{I}}, r_{\mathrm{f}}^{\mathrm{P}}, T\right)}}+\frac{r_{\mathrm{f}}^{\mathrm{I}}+2 r_{\mathrm{u}}^{\mathrm{P}}}{\sqrt{G\left(r_{\mathrm{u}}^{\mathrm{P}}, r_{\mathrm{f}}^{\mathrm{I}}, T\right)}}\right)
$$

The sign of the expression

$$
-\frac{r_{f}^{\mathrm{P}}+2 r_{\mathrm{u}}^{\mathrm{I}}}{\sqrt{G\left(r_{\mathrm{u}}^{\mathrm{I}}, r_{\mathrm{f}}^{\mathrm{P}}, T\right)}}+\frac{r_{\mathrm{f}}^{\mathrm{T}}+2 r_{\mathrm{u}}^{\mathrm{P}}}{\sqrt{G\left(r_{\mathrm{u}}^{\mathrm{P}}, r_{\mathrm{f}}^{\mathrm{T}}, T\right)}}
$$

is the sign of the expression

$$
\left(r_{\mathrm{f}}^{\mathrm{I}} r_{\mathrm{u}}^{\mathrm{I}}+r_{\mathrm{f}}^{\mathrm{P}} r_{\mathrm{u}}^{\mathrm{P}}\right)\left(16 a(a-T)+40 T^{2}\right)+r_{\mathrm{u}}^{\mathrm{I}} r_{\mathrm{u}}^{\mathrm{P}}\left(64(a-T)+160 T^{2}\right)
$$

which is always positive. Thus, it follows that $\partial D^{\mathrm{u}}(T) / \partial T>0$.

The maximum number of bargaining periods the firm would spend negotiating, $I\left(m^{f}(T)\right)$, is given by

$$
\Pi_{i}^{*}\left(T, \delta_{\mathrm{u}}^{\mathrm{P}}, \delta_{f}^{\mathrm{I}}\right)=\left(\delta_{f}^{\mathrm{P}}\right)^{m^{\mathrm{f}}(T)} \cdot \Pi_{i}^{*}\left(T, \delta_{\mathrm{u}}^{\mathrm{I}}, \delta_{\mathrm{f}}^{\mathrm{P}}\right),
$$

from which we obtain

$$
m^{\mathrm{f}}(T)=\frac{1}{\log \left(\delta_{\mathrm{f}}^{\mathrm{P}}\right)} \cdot \log \left[\frac{\Pi_{i}^{*}\left(T, \delta_{\mathrm{u}}^{\mathrm{P}}, \delta_{f}^{\mathrm{I}}\right)}{\Pi_{i}^{*}\left(T, \delta_{\mathrm{u}}^{\mathrm{I}}, \delta_{\mathrm{f}}^{\mathrm{P}}\right)}\right],
$$

and as $\Delta$ approaches zero,

$$
\begin{aligned}
D^{\mathrm{f}}(T)= & \lim _{\Delta \rightarrow \mathbf{0}}\left(m^{\mathrm{f}}(T) \cdot \Delta\right)=-\frac{1}{r_{\mathrm{f}}^{\mathrm{P}}} \cdot \log \left[\left(\frac{r_{\mathrm{u}}^{\mathrm{P}}}{r_{\mathrm{u}}^{\mathrm{I}}}\right)\left(\frac{4 r_{\mathrm{u}}^{\mathrm{I}}+r_{\mathrm{f}}^{\mathrm{P}}}{4 r_{\mathrm{u}}^{\mathrm{P}}+r_{\mathrm{f}}^{\mathrm{I}}}\right)^{2} \cdot\right. \\
& \left.\frac{8 a(a-T) r_{\mathrm{u}}^{\mathrm{P}}+\left(9 r_{\mathrm{f}}^{\mathrm{I}}+38 r_{\mathrm{u}}^{\mathrm{P}}\right) T^{2}+(2 a-T) \sqrt{G\left(r_{\mathrm{u}}^{\mathrm{P}}, r_{\mathrm{f}}^{\mathrm{I}}, T\right)}}{8 a(a-T) r_{\mathrm{u}}^{\mathrm{I}}+\left(9 r_{\mathrm{f}}^{\mathrm{P}}+38 r_{\mathrm{u}}^{\mathrm{I}}\right) T^{2}+(2 a-T) \sqrt{G\left(r_{\mathrm{u}}^{\mathrm{I}}, r_{\mathrm{f}}^{\mathrm{P}}, T\right)}}\right] .
\end{aligned}
$$

which is a positive, finite number. Notice that $D^{\mathrm{f}}(T)$ converges to zero as $r_{i}^{\mathrm{P}}$ and $r_{i}^{\mathrm{I}}$ become close, for $i=\mathrm{u}, \mathrm{f}$. We have 


$$
\begin{aligned}
\frac{\partial D^{\mathrm{f}}(T)}{\partial T}= & \frac{a}{r_{\mathrm{f}}^{\mathrm{P}}\left(2 a^{2}-2 a T+5 T^{2}\right) T} \cdot \\
& \left(-\frac{8 a(a-T) r_{\mathrm{u}}^{\mathrm{I}}+\left(2 r_{\mathrm{u}}^{\mathrm{I}}-9 r_{\mathrm{f}}^{\mathrm{P}}\right) T^{2}}{\sqrt{G\left(r_{\mathrm{u}}^{\mathrm{I}}, r_{\mathrm{f}}^{\mathrm{P}}, T\right)}}+\frac{8 a(a-T) r_{\mathrm{u}}^{\mathrm{P}}+\left(2 r_{\mathrm{u}}^{\mathrm{P}}-9 r_{\mathrm{f}}^{\mathrm{I}}\right) T^{2}}{\sqrt{G\left(r_{\mathrm{u}}^{\mathrm{P}}, r_{\mathrm{f}}^{\mathrm{T}}, T\right)}}\right) .
\end{aligned}
$$

The sign of the expression

$$
-\frac{8 a(a-T) r_{\mathrm{u}}^{\mathrm{I}}+\left(2 r_{\mathrm{u}}^{\mathrm{I}}-9 r_{\mathrm{f}}^{\mathrm{P}}\right) T^{2}}{\sqrt{G\left(r_{\mathrm{u}}^{\mathrm{I}}, r_{\mathrm{f}}^{\mathrm{P}}, T\right)}}+\frac{8 a(a-T) r_{\mathrm{u}}^{\mathrm{P}}+\left(2 r_{\mathrm{u}}^{\mathrm{P}}-9 r_{\mathrm{f}}^{\mathrm{I}}\right) T^{2}}{\sqrt{G\left(r_{\mathrm{u}}^{\mathrm{P}}, r_{\mathrm{f}}^{\mathrm{T}}, T\right)}},
$$

is the sign of the expression

$$
\left(r_{\mathrm{f}}^{\mathrm{I}} r_{\mathrm{u}}^{\mathrm{I}}+r_{\mathrm{f}}^{\mathrm{P}} r_{\mathrm{u}}^{\mathrm{P}}\right)\left(8 a^{2}(a-T)^{2}+22 a(a-T) T^{2}+5 T^{4}\right)-r_{\mathrm{f}}^{\mathrm{I}} r_{\mathrm{f}}^{\mathrm{P}}\left(36 a(a-T) T^{2}+90 T^{4}\right),
$$

which is always positive since $\bar{\alpha}<\widehat{\alpha}$. Thus, it follows that $\partial D^{\mathrm{f}}(T) / \partial T>0$. The maximum real delay time before reaching an agreement is given by

$$
D(T)=\min \left\{D^{\mathrm{u}}(T), D^{\mathrm{f}}(T)\right\} .
$$

In case of separated markets, the maximum number of bargaining periods the union would spend negotiating, $I\left(m^{\mathrm{u}}(T=\infty)\right)$, is given by

$$
U_{i}^{*}\left(T=\infty, \delta_{\mathrm{u}}^{\mathrm{I}}, \delta_{\mathrm{f}}^{\mathrm{P}}\right)=\left(\delta_{\mathrm{u}}^{\mathrm{P}}\right)^{m^{\mathrm{u}}(T=\infty)} \cdot U_{i}^{*}\left(T=\infty, \delta_{\mathrm{u}}^{\mathrm{P}}, \delta_{\mathrm{f}}^{\mathrm{I}}\right),
$$

from which we obtain

$$
m^{\mathrm{u}}(T=\infty)=\frac{1}{\log \left(\delta_{\mathrm{u}}^{\mathrm{P}}\right)} \cdot \log \left[\left(\frac{1-\sqrt{\delta_{\mathrm{f}}^{\mathrm{P}}}}{1-\sqrt{\delta_{\mathrm{f}}^{\mathrm{I}}}}\right)\left(\frac{1-\delta_{\mathrm{u}}^{\mathrm{P}} \sqrt{\delta_{\mathrm{f}}^{\mathrm{I}}}}{1-\delta_{\mathrm{u}}^{\mathrm{I}} \sqrt{\delta_{\mathrm{f}}^{\mathrm{P}}}}\right)\right],
$$

and as $\Delta$ approaches zero

$$
D^{\mathrm{u}}(T=\infty)=\lim _{\Delta \rightarrow \mathbf{0}}\left(m^{\mathrm{u}}(T=\infty) \cdot \Delta\right)=-\frac{1}{r_{\mathrm{u}}^{\mathrm{P}}} \cdot \log \left[\left(\frac{2 r_{\mathrm{u}}^{\mathrm{P}}+r_{\mathrm{f}}^{\mathrm{I}}}{2 r_{\mathrm{u}}^{\mathrm{I}}+r_{\mathrm{f}}^{\mathrm{P}}}\right)\left(\frac{r_{\mathrm{f}}^{\mathrm{P}}}{r_{\mathrm{f}}^{\mathrm{I}}}\right)\right],
$$

which is a positive, finite number. Notice that $D^{\mathrm{u}}(T=\infty)$ converges to zero as $r_{i}^{\mathrm{P}}$ and $r_{i}^{\mathrm{I}}$ become close, for $i=\mathrm{u}$,f. Similarly, the maximum number of bargaining periods the firm would spend negotiating, $I\left(m^{\mathrm{f}}(T=\infty)\right)$, is given by

$$
\Pi_{i}^{*}\left(T=\infty, \delta_{\mathrm{u}}^{\mathrm{P}}, \delta_{f}^{\mathrm{I}}\right)=\left(\delta_{\mathrm{f}}^{\mathrm{P}}\right)^{m^{\mathrm{f}}(T=\infty)} \cdot \Pi_{i}^{*}\left(T=\infty, \delta_{\mathrm{u}}^{\mathrm{I}}, \delta_{\mathrm{f}}^{\mathrm{P}}\right),
$$

from which we obtain

$$
m^{\mathrm{f}}(T=\infty)=\frac{1}{\log \left(\delta_{\mathrm{f}}^{\mathrm{P}}\right)} \cdot \log \left[\left(\frac{\delta_{f}^{\mathrm{I}}}{\delta_{\mathrm{f}}^{\mathrm{P}}}\right)\left(\frac{1-\delta_{\mathrm{u}}^{\mathrm{I}} \sqrt{\delta_{\mathrm{f}}^{\mathrm{P}}}}{1-\delta_{\mathrm{u}}^{\mathrm{P}} \sqrt{\delta_{\mathrm{f}}^{\mathrm{I}}}}\right)^{2}\left(\frac{1-\delta_{\mathrm{u}}^{\mathrm{P}}}{1-\delta_{\mathrm{u}}^{\mathrm{I}}}\right)^{2}\right],
$$


and as $\Delta$ approaches zero,

$$
D^{\mathrm{f}}(T=\infty)=\lim _{\Delta \rightarrow \mathbf{0}}\left(m^{\mathrm{f}}(T=\infty) \cdot \Delta\right)=-\frac{1}{r_{\mathrm{f}}^{\mathrm{P}}} \cdot \log \left[\left(\frac{2 r_{\mathrm{u}}^{\mathrm{I}}+r_{\mathrm{f}}^{\mathrm{P}}}{2 r_{\mathrm{u}}^{\mathrm{P}}+r_{\mathrm{f}}^{\mathrm{I}}}\right)^{2}\left(\frac{r_{\mathrm{u}}^{\mathrm{P}}}{r_{\mathrm{u}}^{\mathrm{I}}}\right)^{2}\right] .
$$

Then, the maximum real delay time before reaching an agreement is given by

$$
D(T=\infty)=\min \left\{D^{\mathrm{u}}(T=\infty), D^{\mathrm{f}}(T=\infty)\right\} .
$$

\section{References}

[1] Abowd, J.M. and J.S. Tracy, 1989, "Market Structure, Strike Activity, and Union Wage Settlements," Industrial Relations 28, 227-250.

[2] Andersen, T.M., N. Haldrup and J.R. Sørensen, 2000, "EU Labour Markets: Effects of Greater Product Market Integration", Economic Policy 30, 105-133.

[3] Ausubel, L.M., P.C. Cramton and R.J. Deneckere, 2002, "Bargaining with Incomplete Information," in R.J. Aumann and S. Hart (eds.), Handbook of Game Theory, Vol.3, 1897-1945 (Amsterdam: Elsevier Science Publishers).

[4] Binmore, K.G., A. Rubinstein, and A. Wolinsky, 1986, " The Nash Bargaining Solution in Economic Modelling," Rand Journal of Economics 17, 176-188.

[5] Cai, H., 2003, "Inefficient Markov Perfect Equilibria in Multilateral Bargaining," Economic Theory 22, 583-606.

[6] Cheung, F.K. and C. Davidson, 1991, "Bargaining Structure and Strike Activity," Canadian Journal of Economics 24, 345-371.

[7] Cramton, P.C., 1992, "Strategic Delay in Bargaining with Two-Sided Uncertainty," Review of Economic Studies 59, 205-225.

[8] Cramton, P.C. and J.S. Tracy, 1994, "The Determinants of U.S. Labor Disputes," Journal of Labor Economics 12, 180-209.

[9] Cramton, P.C. and J.S. Tracy, 2003, "Unions, Bargaining and Strikes," in J.T. Addison and C. Schnabel (eds.), International Handbook of Trade Unions, Chapter 3, 86-117 (Cheltenham, UK: Edward Elgar).

[10] Cutcher-Gershenfeld, J., Kochan, T. and J. Calhoun-Wells, 1998, ” How Do Labor and Management View Collective Bargaining," Monthly Labor Review 121(Oct.), 23-31. 
[11] Davidson, C., 1988, "Multiunit Bargaining in Oligopolistic Industries," Journal of Labor Economics 6, 397-422.

[12] Dowrick, S., 1989, "Union-Oligopoly Bargaining," The Economic Journal 99, 11231142.

[13] Horn, H., and A. Wolinsky, 1988, "Bilateral Monopolies and Incentives for Merger", Rand Journal of Economics 19, 408-419.

[14] Huizinga, H., 1993, "International Market Integration and Union Wage Bargaining", Scandinavian Journal of Economics 95, 249-255.

[15] Kennan, J., 1986, "The Economics of Strikes," in O. Ashenfelter and R. Layard (eds.), Handbook of Labor Economics, Vol.2, 1091-1137 (Amsterdam: Elsevier Science Publishers).

[16] Kennan, J. and R. Wilson, 1989, "Strategic Bargaining Models and Interpretation of Strike Data," Journal of Applied Econometrics 4, S87-S130.

[17] Kennan, J. and R. Wilson, 1993, "Bargaining with Private Information," Journal of Economic Literature 31, 45-104.

[18] Mauleon, A. and V. Vannetelbosch, 2003, "Market Competition and Strike Activity," International Journal of Industrial Organization 21(5), 737-758.

[19] Mauleon, A. and V. Vannetelbosch, 2004, "Strategic Union Delegation and Incentives for Merger", forthcoming in Applied Economics Letters.

[20] Mauleon, A. and V. Vannetelbosch, 2005, "Strategic Union Delegation and Strike Activity," Canadian Journal of Economics 38(1), 149-173.

[21] Munch,J.R. and J.R. Skaksen, 2002, "Product Market Integration and Wages in Unionized Countries," Scandinavian Journal of Economics104, 289-299.

[22] Naylor, R., 1998, "International Trade and Economic Integration when Labour Markets are Generally Unionised", European Economic Review 42, 1251-1267.

[23] Pencavel, J., 1991, Labor Markets under Trade Unionism: Employment, Wages, and Hours (Oxford: Basil Blackwell).

[24] Ross, A.M., 1948, Trade Union Wage Policy (University of California Press, Berkeley, $\mathrm{CA})$. 
[25] Rubinstein, A., 1982, "Perfect Equilibrium in a Bargaining Model," Econometrica $50,97-109$.

[26] Sørensen, J.R., 1993, "Integration of Product Markets when Labour Markets are Unionized", Recherches Economiques de Louvain 59, 485-502.

[27] Tracy, J.S., 1986, "An Investigation into the Determinants of U.S. Strike Activity," American Economic Review 76, 423-436.

[28] Watson, J., 1998, " Alternating-Offer Bargaining with Two-Sided Incomplete Information," Review of Economic Studies 65, 573-594. 
Département des Sciences Économiques de l'Université catholique de Louvain

Institut de Recherches Économiques et Sociales

Place Montesquieu, 3

1348 Louvain-la-Neuve, Belgique 